\section{Public Disclosure and Environmental Performance in Laguna de Bay Region, Philippines}

\section{Ria Lambino* \\ ${ }^{a}$ Kyoto University, Graduate School of Global Environmental Studies, Kyoto City, Japan}

Received: March 30, 2013/ Accepted: April 29,2013

\begin{abstract}
The growing interest in information disclosure as a means of curbing industrial pollution merits closer study especially for the case of developing nations who are characterized by weak monitoring and enforcement capacities. Disclosures are claimed to go beyond traditional regulation and market based instruments by activating public pressure for businesses to behave more sustainably. An analysis of the environmental performance rating and disclosure program in the Laguna de Bay region was undertaken to determine effectiveness of this strategy and how it worked. While findings indicated some trends towards improvement rather than decline or maintenance of ratings, the theory-based evaluation revealed a number of implementation inadequacies that hampered the program's potential to be effective. There was limited evidence of public pressure due to weak information flows and insufficient dissemination platforms. Furthermore, public pressure, other mechanisms such as enhanced regulatory threats on top of disclosure may be more effective to get businesses to behave more sustainably.
\end{abstract}

Keywords: information disclosure; pollution control; environmental performance.

\section{Abbreviations:}

\begin{tabular}{|lll|}
\hline BOD & $:$ & Biological Oxygen Demand \\
PDP & $:$ & Public Disclosure Program \\
LLDA & $:$ & Laguna Lake Development Authority \\
\hline
\end{tabular}

\section{Introduction}

Despite the increasingly urgent calls for sustainable development, production processes are still far from sustainable especially in developing countries. The challenge of limiting and minimizing industrial waste and pollution emissions in these countries are incumbent on government agencies that are often characterized with weak regulatory capacities, lack of budget and technical capabilities

*Corresponding Author

Tel: +819039486840; E-mail: ria.lambino@gmail.com
Alternate strategies such as information disclosure are hoped to overcome these deficiencies in order to address these environmental issues [1]. Disclosure is premised on the concept that information when made available to the public serves as a pressure for the disclosed entity to change behaviour for the better. Listings of companies and the toxic substances they released as published through programs such as Toxics Release Inventories (US) and Pollutant Release and Transfer Registers (in countries like Japan, Canada, Australia, EU), have led to subsequent reductions in company emissions. Their increasing use and popularity in pollution control merit closer study especially for the case of developing nations.

In the mid-199os, with the help of World Bank, developing countries formulated information strategies in the form of disclosure of environmental performance of companies using a color-coded rating system. Businesses that behave sustainably are awarded and honoured while non-complying or poor performers are labelled and shamed. The premise is that when reputations are at stake, businesses will aim to behave more sustainably. Multiple benefits such as empowerment of stakeholders, improved environmental compliance and the promise of low cost of implementation have attracted government agencies to adopt these disclosure programs. While some country-specific researches in China, Indonesia and India have attested to the effectiveness of disclosure strategies[1] [2] [3], more recent papers have since watered down some of these earlier expectations--public pressure may not be strong enough [4]; net effectiveness of the strategies are being questioned [5] and long-term effects have yet to be observed [6].

This paper attempts to build up on this literature by providing additional critique and insight through the analysis of the public disclosure program aimed at addressing the rising pollution levels caused by industries in the Laguna Lake region, a center of urban and industrial development in the Philippines. The Philippines is one of the countries that have embraced public disclosure for pollution control but there have been no studies that have evaluated these programs' impacts and the mechanisms by which they work. This study seeks to answer the following questions: Is the public disclosure program effective in making businesses behave more sustainably in the Laguna de Bay region? How did it work? How did it not work?The paper will attempt to clarify under what conditions the potentials of disclosure strategies can be generated and if the purported benefits are real or overrated.

\section{Methodology and Analytical Framework}

A qualitative case study methodology was employed by the research. The environmental performance databases for 4 disclosure periods (2006 to 2009) were accessed from the regulatory agency, Laguna Lake Development Authority (LLDA) and were analysed to determine trends for improvement (towards more sustainable behaviour), status quo or decline. The movement to a higher rating (especially BLUE or GREEN) would indicate that companies were behaving more sustainably or at the very least, complying with pollution standards. In order to generate insight and understanding in the design, implementation and outcomes of the program, primary data were generated from interviews comprising of open-ended questions to key personnel of the program Secretariat and other officers of the LLDA. Openended questionnaires were also administered to representative Pollution Control Officers of companies who were included in the program. Table 1 lists the key informants interviewed for the study. 
Other qualitative data on outcomes and improvements were generated from secondary data sources such as project reports, evaluations and previous research studies.

This particular study furthermore tested the claims of the Public Disclosure Program (PDP) against the outcomes observed by making use of program logic and implementation theory framework [7].

Table 1List of key informants interviewed for the case study

\begin{tabular}{|c|c|}
\hline $\begin{array}{l}\text { Number of } \\
\text { interviewees }\end{array}$ & Interviewees \\
\hline 9 & $\begin{array}{l}\text { Key personnel of the Laguna Lake Development } \\
\text { Authority }\end{array}$ \\
\hline 6 & $\begin{array}{l}\text { Public Disclosure Program Monitoring Group (multi- } \\
\text { sectoral group composed of representatives from an } \\
\text { NGO, local government units, business sector and } \\
\text { LLDA) }\end{array}$ \\
\hline 1 & Company consistently rated compliant \\
\hline 2 & Companies consistently rated non-compliant \\
\hline 2 & $\begin{array}{l}\text { Companies which improved ratings (from non- } \\
\text { compliant to compliant) }\end{array}$ \\
\hline
\end{tabular}

This particular study furthermore tested the claims of the Public Disclosure Program (PDP) against the outcomes observed by making use of program logic and implementation theory framework [7]. This essentially involved determining the logic behind the program (mechanisms, theories and justification of the public disclosure policy), identifying steps undertaken from input to outcomes and correlating this with the actual outcomes observed.The program and implementation logic for the public disclosure program was generated by the author through examination of program documents, reports, presentation materials as well as interviews with program implementers. Additional primary data on implementation activities were generated through process observations which consisted of sitting in on monitoring meetings and 5 technical conferences during the period Sept 3 to October 6, 2010, recording and taking notes on the discussions and observing the actual conduct of the activities.

The PDPis premised on the fact that companies are sensitive to reputation, so information flows were deemed important to project outcomes. There was a lack of documentation by the program secretariat about the extent of print media coverage for the Public Disclosure Program so an intensive online search was conducted. Search engines such as Google, Yahoo, Yehey, and Bing were extensively searched to determine exposure of rated companies' sustainable (or non-sustainable) practices using various permutations of keywords linked to the PDP. Websites of major newspapers and some TV stations were also searched and the results were utilized as primary data to trace and characterize information flows.

\section{Program Contents and Outcomes}

\subsection{Context}

LagunaLake is strategically situated in the country's center of urban and industrial development and is important as a source of agricultural food commodities, industrial raw materials and manufactured goods but has become a repository of domestic and industrial wastes from its surroundings. An evaluation study revealed that the permitting, monitoring and enforcement procedures were characterized by an inefficient tracking system as well as a lack of information materials for the public [8] and that there was a need for low-cost complementary approaches to the regulatory mechanisms and market-based instruments currently being employed by the Laguna Lake Development Authority (LLDA), a quasi-government agency tasked to oversee management of the region. To address these gaps, an information disclosure program for the region was designed in 2005. The Public Disclosure Program employs color-coded ratings of the environmental performance of companies and dissemination of these results to the public.

\subsection{Rating Criteria}

The disclosure program in the Laguna de Bay Region rates the degree of pollution discharged by establishments as well as the extent of efforts by company management in controlling these discharges. The criteria includes only water-related parameters since these are the data available in the LLDA's monitoring database. These include "hard" criteria such as technical data on indicators for pollution discharge and "soft" criteria such as administrative requirements like payment of pollution charges, user fees and submission of self-monitoring reports [9]. The Biological Oxygen Demand (BOD) is the primary determinant for compliance being used and based on prescription set by Departmental Administrative Order No. 35 Series of 1990. The program then assigns color ratings according to the system as shown in Table 2.

Table 2 Color Coded Rating System for the Public Disclosure Program

\begin{tabular}{|c|c|}
\hline $\begin{array}{l}\text { Broad } \\
\text { Category }\end{array}$ & Description /Criteria \\
\hline $\begin{array}{l}\text { BLACK } \\
\text { (very bad) }\end{array}$ & $\begin{array}{l}\text { Failed standards for average BOD } \\
\text { Committed manipulation of effluent discharge } \\
\text { Obstruction of authorized inspection } \\
\text { Verified pending legal cases } \\
\text { with Cease and desist order or ex-parte Order }\end{array}$ \\
\hline $\begin{array}{l}\text { RED } \\
\text { (bad) }\end{array}$ & $\begin{array}{l}\text { Average BOD exceeds effluent standards but with } \\
\text { considerable effort to reduce pollution } \\
\text { At least } 75 \% \text { sampling results in compliance } \\
\text { With well-documented efforts to reduce pollution } \\
\text { With pending legal cases }\end{array}$ \\
\hline $\begin{array}{l}\text { BLUE } \\
\text { (good) }\end{array}$ & $\begin{array}{l}\text { Effluents consistently within standards } \\
\text { In full compliance with all regulatory requirements } \\
\text { including submission of reports } \\
\text { Well maintained wastewater treatment facility }\end{array}$ \\
\hline $\begin{array}{l}\text { GREEN } \\
\text { (Very good) }\end{array}$ & $\begin{array}{l}\text { Rated Blue in the previous rating period } \\
\text { Effluents better than standards by at least } 20 \% \\
\text { Has well functioning monitoring equipment } \\
\text { Has discharge points accessible to inspection }\end{array}$ \\
\hline
\end{tabular}

Source: LLDA

\subsection{Rating and Disclosure Process}

Based on interviews with the Secretariat of the program, three sets of databases are used to evaluate the industries' environmental performance: 1)the Results of Laboratory Analysis (ROLA) database, 2) Self-Monitoring Report (SMR)database and 3) Legal Division database. The average Biological Oxygen Demand records of each establishment are obtained from the laboratory analyse and then cross-referenced to determine whether an establishment has regularly submitted the required SMR which is an administrative policy. Then each establishment will be cross-referenced with the Legal Division to determine if an establishment has a pending case/s from any violation/s after which the initial rating is undertaken based on Table 1.

Candidates for BLUE and GREEN ratings undergo a validation process such as monitoring and site visits. Whereas RED and BLACK ratees are notified and are given enough time to present themselves during technical conferences. Ratings are then finalized presented to a multi-sectoral Program Monitoring Group who submit the final list to the LLDA General Manager for approval and then disclosed through an event organized to award the best performers. Press Releases are prepared by the LLDA Public Information unit and disseminated to media representatives from various television, newspaper and radio networks. 


\subsection{Outcomes}

Improvement in terms of environmental performance of companies rated and disclosed may be reflected in changes of their ratings over a period of time. Table 4presents the number of companies with a particular rating from the first to the fourth cycle. This table shows that while an additional number of establishments have been added to the program per cycle, the number of disclosed ratings is less than the total number of industries included in the program. This indicates that a number of companies do not have ratings or are not being monitored for follow-up.

Table 3 Results of the color-coded performance ratings under the Public Disclosure Program from 2006 to 2009

\begin{tabular}{lcccc}
\hline COLOR Rating & $\begin{array}{c}\mathbf{1}^{\text {st }} \text { cycle } \\
(\mathbf{2 0 0 6})\end{array}$ & $\begin{array}{c}\mathbf{2}^{\text {nd }} \text { cycle } \\
(\mathbf{2 0 0 7})\end{array}$ & $\begin{array}{c}3^{\text {rd }} \text { cycle } \\
(\mathbf{2 0 0 8})\end{array}$ & $\begin{array}{c}4^{\text {th }} \text { cycle } \\
(\mathbf{2 0 0 9})\end{array}$ \\
\hline GREEN & - & 1 & 15 & 29 \\
BLUE & 10 & 47 & 39 & 28 \\
RED & 4 & 27 & 51 & 68 \\
BLACK & 13 & 26 & 8 & 4 \\
Total \# disclosed & 27 & 103 & 113 & 129 \\
Total \# part of & 28 & 11 & 50 & 86 \\
previous cycles not & & & & \\
disclosed & & & & \\
Total \# included in & 56 & 115 & 165 & 215 \\
PDP & & & & \\
\hline
\end{tabular}

Notes: 1. Table generated based on data from PDP Secretariat File Documents. 2. No disclosure are those companies included in the program but were not disclosed

The lack of follow-up rating for a number of the establishments in various cycles made it difficult to track the rating behaviour of the companies in a time-series manner. Instead, the study tried to track the change in behaviour of the companies by looking at data of their initial rating in the program and comparing it with their rating in the latest cycle $\left(4^{\text {th }}\right.$ cycle in 2009) of the program. For this particular analysis, the study considered the first 3 batches only with a total of 165 companies.

Table 4 Monitoring of changes in environmental ratings of 165 companies under Public Disclosure Program (initial ratings vs. final ratings

\begin{tabular}{|c|c|c|c|c|c|c|c|}
\hline \multirow{3}{*}{$\begin{array}{l}\text { Initial } \\
\text { Rating }\end{array}$} & \multicolumn{7}{|c|}{2006 to 2009 ) } \\
\hline & $\mathbf{A}$ & B & $\mathrm{C}$ & D & $\mathbf{E}$ & F & G \\
\hline & 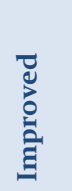 & 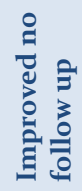 & $\begin{array}{l}\text { :ू } \\
\text { J } \\
\text { ป } \\
0 \\
Z\end{array}$ & 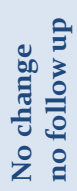 & 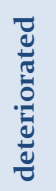 & 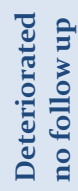 & 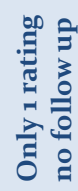 \\
\hline BLACK & $16(3)$ & 12 & $\mathrm{o}$ & 5 & $\mathrm{o}$ & $\mathrm{o}$ & 17 \\
\hline RED & 10 & 6 & 18 & 7 & o & o & 15 \\
\hline BLUE & 25 & 5 & 6 & 5 & 1 & 2 & 12 \\
\hline GREEN & o & o & o & o & o & o & o \\
\hline Total: 165 & 54 & 23 & 24 & 17 & 1 & 2 & 44 \\
\hline
\end{tabular}

Note: This table was generated from rating results of the PDP for 165 firms based on an establishment's initial rating to its final rating in 2009. The number in parenthesis indicates the improvement in ratings by 2 or more steps.

Table 4 tracks the movement of the ratings of the company included in the first 3 batches. The leftmost column indicates the initial color ratings. Companies whose ratings progressed from a lower level to a higher level are indicated in column A. The number in parenthesis indicates that these companies moved up by 2 or 3 levels (16 companies improved from BLACK to RED and 3 companies from BLACK to BLUE or GREEN). The number of companies that initially improved but did not have any follow-up ratings are presented in column $B$. Column $C$ shows number of companies with no changes (succeeding ratings remained the same or were maintained) while column $\mathrm{D}$ indicates those that initially maintained ratings (at least 2 rating cycles) but did not have a final rating in the $4^{\text {th }}$ cycle disclosure. Ratings which deteriorated are tabulated in column $\mathrm{E}$ and those which also declined but did not have a final rating in 2009, in column F. The last column, G indicates that the companies were only rated once and did not have a final rating in the $4^{\text {th }}$ cycle disclosure.

Improvement of rating was observed for 54 of the establishments from batch 1 to 3 (33\%). Twenty-three also initially improved but did not have any follow-up rating in the $4^{\text {th }}$ cycle. No changes in color ratings were observed for 24 establishments (15\%) a2nd 17 others who had no follow-up monitoring. Three firms were observed to decline from BLUE to RED which meant that they became noncompliant for the $4^{\text {th }}$ cycle although for 2 of these, the final status is not known. What is interesting to note is that there were 44 firms $(27 \%)$ who only had one rating and no follow-up rating, so behaviour change in these firms are not known.

Based on Table 4, the compliance status of firms by 2009 were identified (as shown in Table 5). As of the 2009 disclosure, companies with compliant status totaled 44 (3 originally BLACK which became BLUE/GREEN, 10 originally RED which became BLUE, 25 originally BLUE which improved to GREEN and 6 maintained BLUE) - around $27 \%$ of the companies analyzed. On the other hand, 35 companies can still be considered noncompliant (16 BLACK rated companies improved to RED, 18 RED maintained and 1 initially BLUE which declined to RED). This accounted for $21 \%$ of the rated companies in the first 3 batches. The remaining $52 \%$ of the companies from batch 1 to 3 had incomplete ratings or were not completely monitored (they had no rating for the last cycle) so conclusion about their compliance status were not known.

Table 5 Status of compliance of 165 companies as of 2009 disclosure

\begin{tabular}{lcc}
\hline Status & \# of firms & Percentage \\
\hline Firms with compliant status & 44 & $27 \%$ \\
Compliant firms with no follow up & 30 & $18 \%$ \\
rating & & \\
Firms with noncompliant status & 35 & $21 \%$ \\
Non-compliant firms with no follow up & 56 & $34 \%$ \\
ratings & 165 & $100 \%$ \\
Total & & \\
\hline
\end{tabular}

The PDP secretariat explained that establishments without ratings did not have records in the Results of Laboratory Analysis database for the considered evaluation period and that others may have shut down their operation or may have secured interconnection with water treatment facility service providers. Limitations with human resources for monitoring, lack of laboratory support (in the case of data deficiencies), as well as other administrative and implementation factors were also cited. This was unfortunate as follow up ratings would have ensured complete data set for tracking of changes and would have provided much insight as to the program's effectiveness. It is especially important due to the fact that of those who only had one rating or no follow-up ratings, there were 22 BLACK and 22 RED companies. For a program whose goal was to improve compliance, this should have been very important to monitor. This study finds the lack of baseline data for monitoring changes over time and the deficiency of the monitoring processes challenging, making the conduct of a more rigorous analysis of the effectiveness of the program as a whole very difficult.

\section{Program Logic and Implementation Theory of the PDP}

Aside from monitoring deficiencies as observed in the lack of ratings for a number of the companies included in the PDP, it was 
suspected that the program would have other implementation and operational issues as well so program logic models were turned to as a framework to aid further analysis. In order to flesh out the mechanisms of the information disclosure that worked and did not work, it was necessary to look deeper into the actual "realities" of the program.

The main mechanism identified by the program implementers is the use of public pressure: "the PDP makes use of information to create public pressure and motivates the polluters to reduce their pollution and comply with environmental standards"[10](with emphasis by the author); and "the PDP uses media publicity as a tool to create public pressure" [11].The Technical Report, Design of the Public Disclosure Program for the Laguna de Bay Region has this specific objective: "to inform the public of the key stakeholders' performance in the Laguna de Bay Region in terms of compliance with and promotion of environmental standards" [9].

The program logic reconstructed and shown in Figure 1 traces the actual activities and steps that the program undertakes which it deems necessary to meet its objectives ( $1^{\text {st }}$ column: implementation theory/logic) and the responses and the step-wise mechanisms that will enable the program to reach its desired goals ( $2^{\text {nd }}$ column: program theory/logic). Program implementers in general assume that when certain activities are conducted, then the outcomes they hope for will be achieved. In the case of the PDP, some intermediate outcomes are assumed: for example, it is assumed that the disclosure event organized by the program will be well-attended and that media will not just cover the event but will find the ratings newsworthy enough in order to circulate it as news in their respective broadcast medium. There are then two possibilities for the public pressure mechanism to be generated: 1) that the strategy of honouring and shaming will generate positive action from companies and 2) that direct pressure from external agents (i.e. local communities, NGOs, clients, finance institutions)in the form of product boycotts, complaints, withdrawn investments will motivate companies to improve performance.

Program Activities

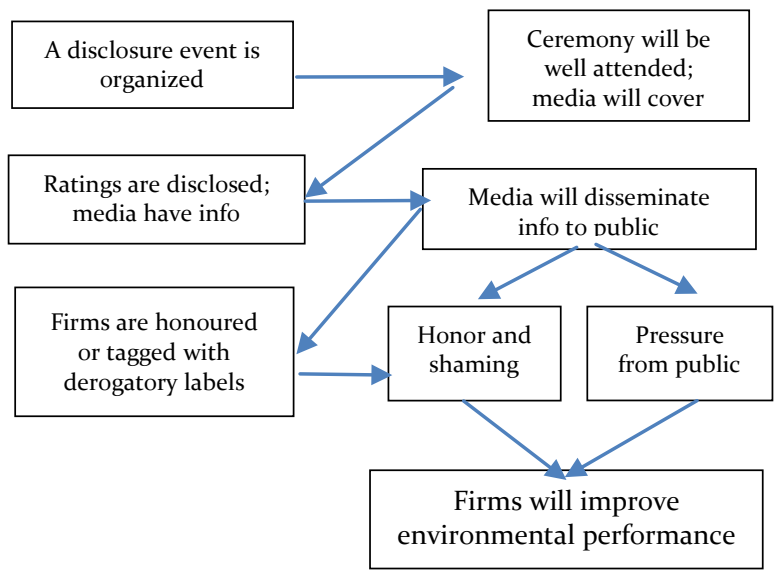

Figure 1 Program logic generated by the author for the PDP

The honouring and shaming function being harnessed in the PDP is considered by the LLDA as a "carrot and stick" approach [12]. The commendation for establishments with good performance serves as an incentive (carrot), and the shaming of those with poor performance serves as a sanction (stick). This is based on the premise that companies are reputationally sensitive and would react rationally to information that will enhance or damage their brand or company images. In the Philippines, shaming campaigns have been attempted in the past to stop drug abuse, prevent jay walking as well as to expose polluting firms in the 1980 s.

Pressures external to the companies are also assumed to be at work through the PDP. The logic is that when the rating results reach the public, they will be empowered such that they are moved to generate pressure on the companies to comply with environmental standards. Literature have provided some evidence in other countries that this feedback comes in the form of pressure from various groups such as local communities, NGOs, investors, stock market to the bad performers to comply with environmental regulations [2] [13]. For the good performers, the public are surmised to also provide positive feedback through improved sales, higher consumer confidence and improved brand reputation. One assumption of the PDP program logic is that the rating results are news worthy, that it creates media scrutiny and that activities such as boycotting of products, withdrawal of stocks/financial support, censure etc. will be undertaken by local communities, market, clients and NGOs as a response to this information. The external pressure is assumed to be strong enough such that businesses actually respond by undertaking actions to improve compliance.

\subsection{Implementation Platforms and Information Flows}

The PDP is premised on the use and disclosure of information, and as such information flows are deemed very important to project effectiveness. Access to information would be important if external actors are to be empowered or if shaming (and honouring) were to occur.

The author generated Figure 2 which describes the information flows through the platforms utilized for the program. The study makes use of this figure as a means to analyze the effectiveness of the implementation platforms currently utilized by the PDP. It shows clearly that information about the rating results emanates from the LLDA. Here, it is observed that the regulatory authority acts as a "facilitator" and provider of information flows to the companies and the public in general.

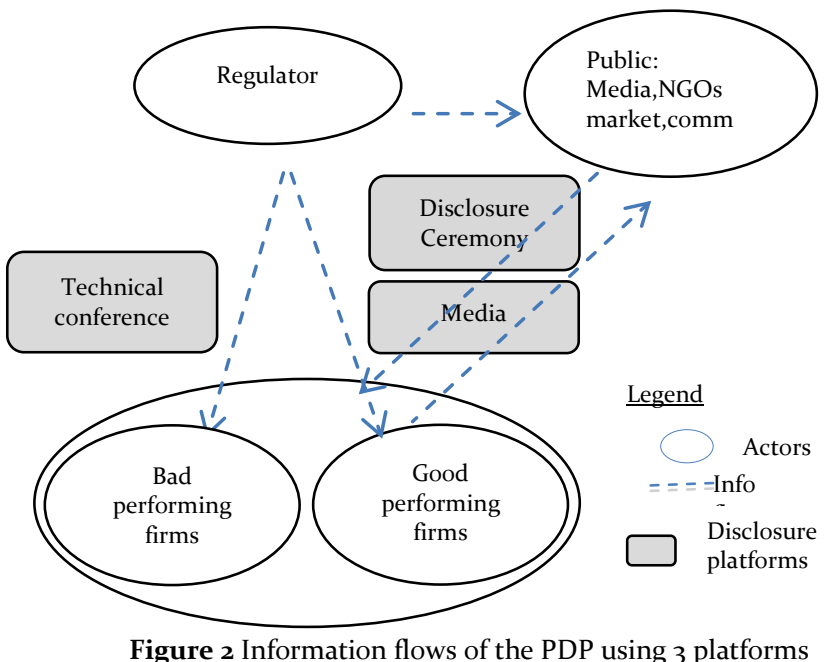

Two main platforms for disclosure were used by the program to disseminate information: the conduct of a disclosure event and media exposure. A third activity, Technical Conferences which serve as platforms for the PDP to directly disclose results to the negatively rated companies were also examined and analysed.

\subsubsection{Disclosure Ceremony}

Special events to award the good performers were organized for the first 3 cycles of the PDP. For the fourth cycle, disclosure was included as part of the program for the 2009 Annual Learning Forum for the stakeholders in the region. 
During the disclosure ceremony, the GREEN rated companies were given plaque awards while BLUE-rated companies receive certificates. The rest of the ratings (RED and BLACK) were announced as a "grande finale" to the program usually through an audio-visual presentation with names of the corresponding companies flashed onscreen.

An average of 100 participants to the first three disclosure events and 600 participants for the fourth disclosure were estimated. Except for the last cycle, participants to these events were composed mainly of representatives of the good performing companies (BLUE and GREEN ratees), representatives from donor agencies and the press. Even if the event was open to all, no formal invitations were sent to RED and BLACK companies nor were they obviously likely to attend the event as doing so will only lead to them being embarrassed because of their noncompliant status.

\section{Analysis}

The information flow from the program to the rated companies would indicate strong flow for the good performers. However, it is to be noted that events designed for disclosure and awarding ceremonies alone provide only weak information flow to the negatively-rated companies as they are not likely to be participants to these events. Thus, actual "shaming" are not seen to be activated for these events. Furthermore, an audience size of around 100 would imply a relatively weak information flow as this is small compared to the number of companies in the region and limited compared to the size and representation of stakeholders in the area, with the exception of the $4^{\text {th }}$ disclosure in that it was integrated into the Annual Learning Forum in 2009, and the event was attended by an estimated 600 participants comprising of representatives of all major stakeholders of the Laguna De Bay Region [14]. This type of event may be more effective because more stakeholder groups in the region are able to receive the information and can thus provide more feedback to the rated companies whether they are being honoured or shamed.

\subsubsection{Media Disclosures}

During the disclosure ceremonies, media representatives are invited and provided fact sheets about the program as well as the names and ratings for their reference. The press forum at the end allows the media to raise some questions. Press releases are also prepared by the Public Information Unit of the LLDA and distributed to media networks. The extent of media exposure was tracked online. Table 6 shows the results of the online search and presents the names and number of newspapers where rating results appeared (total of 7 news articles). For the first disclosure ceremony, 2 major national newspapers carried the pollution news and named the 13 BLACK ratees. The second disclosure ceremony generated 3 newspaper articles-the first named 3 GREEN ratees, and 26 BLACK ratees, the second named the BLACK ratees only and the third newspaper carried information about the program and the general results but was careful not to mention the actual names of the companies. The third disclosure was carried in 2 newspapers focusing on the BLACK ratees with one mentioning the 15 GREEN ratees as well. There were no print media articles found for the fourth disclosure cycle.

All of the articles mentioned the "polluters" (BLACK ratees) and though some named the good performers/awardees, it was observed that the headlines and focus stayed on the bad performers (BLACK rates) with only a couple naming the GREEN companies. It is to be pointed out that companies rated BLUE and RED were not named in any of the media articles. As a platform for which to generate public pressure or reputational pressure, media disclosures are found to be limited in general to reporting only the extreme ends of the performance spectrum-those performing very well and those performing very poorly. As such, reputational incentives or sanctions and/or public pressures through this platform may be strongest for BLACK-rated companies, followed by GREEN-rated companies and none for those rated in between. An interview with the Pollution Control Officer of a RED-rated company confirm this observation-he claims that though they have been rated RED and are considered noncompliant, his company has never been exposed in any media disclosures and as such not been subjected to any reputational sanctions. The study also tried to determine the extent to which the articles about the PDP disclosures have been picked up in subsequent exposures in other websites, blogs, forums and networking sites. Other digital sources such as corporate newsletters and other reports were also tracked.

Table 6 Online tracking of Print Media exposure of the PDP

\begin{tabular}{|c|c|c|c|}
\hline \multirow{2}{*}{$\begin{array}{l}\text { Name of } \\
\text { Newspaper }\end{array}$} & \multirow{2}{*}{ Headlines } & \multicolumn{2}{|c|}{ Contents } \\
\hline & & Positive & Negative \\
\hline $1^{\text {st }}$ cycle: (1) Manila & Laguna Lake & $\mathrm{X}$ & $\mathrm{O}$ \\
\hline Times: June 3o, & watchdog & & names 13 \\
\hline 2006 & $\begin{array}{l}\text { names } 13 \text { big } \\
\text { polluters }\end{array}$ & & $\begin{array}{l}\text { BLACK ratees } \\
\text { only }\end{array}$ \\
\hline $1^{\text {st }}$ cycle:(2) Inquirer & Who are on & $\mathrm{X}$ & 0 \\
\hline June 29, 2006 & $\begin{array}{l}\text { bay's polluter } \\
\text { roster }\end{array}$ & & $\begin{array}{l}\text { names } 13 \\
\text { BLACK rates }\end{array}$ \\
\hline $2^{\text {nd }}$ cycle: $(1)$ & Top fast food & $\bigcirc$ & $\mathrm{O}$ \\
\hline Inquirer, August 17, & chains among & 3 GREEN & names 26 \\
\hline 2007 & $\begin{array}{l}\text { worst Laguna de } \\
\text { Bay polluters }\end{array}$ & named & BLACK \\
\hline $2^{\text {nd }}$ cycle: (2)Manila & Lake officials & $\mathrm{X}$ & $\mathrm{O}$ \\
\hline Standard August & want charter & & names 26 \\
\hline 20,2007 & amended & & BLACK \\
\hline$\frac{2^{\text {nd }} \text { cycle: }}{\text { Bulletin }}$ & $\begin{array}{l}\text { Polluters told to } \\
\text { clean waste }\end{array}$ & $\mathrm{X}$ & $\begin{array}{l}\text { Sectors and } \\
\text { numbers only }\end{array}$ \\
\hline August 21, 2007 & & & but No names \\
\hline $3^{\text {rd }}$ cycle:(1) & 4 Quezon City & $\mathrm{O}$ & $\mathrm{O}$ \\
\hline Inquirer- & firms cited in & names 15 & names 8 \\
\hline September 18, 2008 & $\begin{array}{l}\text { LLDA shame } \\
\text { awards }\end{array}$ & GREEN & BLACK \\
\hline 3rd cycle: (2) & LLDA names & $\mathrm{X}$ & $\mathrm{O}$ \\
\hline Global Pinoy - & eight top & & names 8 \\
\hline September 18, 2008 & $\begin{array}{l}\text { polluters of } \\
\text { Laguna Bay }\end{array}$ & & BLACK, \\
\hline$\frac{4^{\text {th }} \text { cycle }}{\text { None }}$ & - & - & - \\
\hline
\end{tabular}

Some responses from the public and follow-up online activities were monitored for the $2^{\text {nd }}$ disclosure articles as well as $4^{\text {th }}$ disclosure but none for the $1^{\text {st }}$ and $3^{\text {rd }}$ disclosure articles. A response to $^{\text {nd }}$ disclosure was monitored in a public forum discussing the merits of 2 competing fast-food companies in the Philippines. An NGO website also carried an article zooming in on 10 popular food outlets that were rated BLACK and pressured them to clean up their discharges. The same NGO also exhorted the public to boycott the firms but no further activity or follow up was monitored for this particular response. The last disclosure in 2009, generated some follow-up PR activities for the good performing companies as shown by announcements in their corporate website, and internal company newsletters. One beverage manufacturer, who twice received BLUE ratings, issued a number of press releases focusing on the company's environmental achievement in 3 major newspapers that came out 2 months after the $3^{\text {rd }}$ disclosure ceremony.

\section{Analysis}

Despite the fact that almost all tri-media networks were invited and represented in the disclosure ceremonies, not all of them actually pick up and carry the articles in their respective medium. One reason cited by the PDP secretariat during interviews was that Philippine media is prone to patronage politics. The PDP 
secretariat shared an anecdotal experience wherein a major TV network station was prevented from disclosing the rating results to the public due to the fact that one of their major sponsors was BLACK-rated and they were afraid of the company pulling out its sponsorships for an important TV program. It was observed that for the second cycle, one of the newspaper articles which carried the rating results were careful not to mention the actual names of the companies. It is posited that this newspaper was careful to protect the businesses' reputation who may be major sponsors for that newspaper. For the $4^{\text {th }}$ cycle, other more pressing issues which cropped up during the Annual Forum event were carried, which relegated articles about the performance ratings of the PDP to the sidelines.

Interviews with the members of the PDP secretariat revealed that ensuring media to carry the news usually requires a budget which the LLDA as a quasi-government authority does not have. However the program needs to take into consideration the fact that media cannot be assumed to prey on disclosure events for their news all the time. As such alternative means of dissemination should be explored: for example, websites, training programs for pollution control officers, information bulletins for permitting and licensing. The internet has become a tool for improved regulation and administration by the LLDA but it is currently underutilized for the disclosure program.

Responses and follow-up/subsequent disclosures to the news reports indicate some additional reputational sanctions imposed by an NGO and some consumer groups. However, it has been noted that despite the NGO exhortation for product boycotts, no actual consumer protest or direct action were observed.

\subsubsection{Technical Conferences}

The Technical Conferences serve to convey the results of the rating to the red and BLACK rated businesses, discussing with them the details of how and why they were given such ratings. This is a protocol used by the disclosure program to ensure that advance notice was given to the firms before actual disclosure as well as a chance to solicit feedback from companies.

Process observations were conducted by the author in 5 of these technical conferences. The technical conferences were actually short and small meetings ranging from a 2 person meeting (1 PDP representative and 1 company representative) to a 5-person meeting (2 PDP representatives and 3 representatives of a company). The conferences lasted anywhere from 5 minutes to 20 minutes depending on the topics discussed. Some companies undertook their "conferences" via phone calls in lieu of visiting the LLDA office.

These meetings were monitored to be mainly driven by the need to observe protocols prior to media release of negative ratings. Despite a lot of apparent confusion and questions on the agenda for the meeting and the meaning of BLACK and RED ratings, there was limited information about the details of the PDP The shaming function of the PDP was not highlighted in the technical conferences observed as there was no reiteration of the fact that the ratings will be disclosed to the public. There was also a lack of advisory about the disclosure process or even the threat of disclosure. The consequences of having a poor rating such as bad publicity and reputational costs were not shared. These could have been brought about by an assumption that the industries have prior knowledge about the program or it could also be brought upon by time limitations due to the numerous meetings scheduled.

Furthermore, while these meetings seem to be favourable venues for warnings of legal implications of noncompliance as well as encouragement/advice about pursuit of a higher rating or improvement of compliance, these did not seem to be part of the objectives for the technical conferences observed.

\section{Analysis}

Other than a feedback mechanism and protocol about the results of the ratings for the PDP, it was observed that a couple of companies perceived the invitation letter to the technical conference as "threatening" or "alarming". One company who perceived the RED/BLACK rating as another offence repeatedly inquired about additional penalties and fines. On the one hand, regulatory sanctions were not the main purpose of the notification. But on the other hand, the study notes that the use of "RED" and "BLACK" labelling by the LLDA was effective in conveying some sort of threat or sanction to the companies. These seem to indicate that the technical conferences were viewed as an additional venue for regulatory pressure for noncompliant firms. It was also observed that a number of companies were asking for advice on how they can become compliant or how they can improve their performance. One company was persistent in getting some technical advice out of the technical conference by asking how to become BLUE/GREEN and how to be lifted from the RED status). However, the PDP secretariat could not give them any technical advice as it was deemed to be "unethical" for a regulator to give specific advice. The responses and reactions of the companies observed during the technical conferences seem to suggest that more than reputational consequences, companies were very concerned about regulatory sanctions.

This study finds that technical conferences present a number of opportunities for the program to reinforce its goals for compliance and can be utilized as more than just a post-rating protocol. There is an opportunity to provide some sort of compliance assistance to the negatively rated companies or to link them with good performers in the same sector for technology and knowledge sharing.

\subsection{Does disclosure lead to public pressure in the Laguna de Bay Region?}

Reputational pressure and more specifically public pressure, has been widely promoted as the main driver for improved environmental performance by the supporters of information disclosure strategies. This in fact has been the concept that the PDP has subscribed to consciously and in which the activities of the program are patterned.

Interviews conducted with some company representatives about the impact of the program on their company as well as on their environmental performance indicate that to a certain extent, the honouring and shaming function is at work. Three of the Pollution Control Officers of companies who have received awards expressed in interviews that their staff were happy and motivated and it served as an encouragement for them to be more environmentally conscious and to strive to abide by the laws. At the same time, incentives for some regulatory requirements such as longer validity of discharge permits and lesser frequency of submission of SMRs were cited as benefits of getting good awards.

Negative rated company representatives also indicated that ratings matter and affect their reputation. A Pollution Control Officer of a company initially rated BLACK in the first cycle but became BLUE in the fourth expressed that she joined the company during the time when they still had the negative ratings and had been exposed on TV. She saw this as a "problem" and was the one thing she prioritized and personally took care of when she got on board as pollution control officer. She believes that the LLDA had to resort to such tactics because "Filipinos don't follow rules until they learn their lesson. Perhaps, LLDA thought that if companies don't comply then we will disclose and shame them on TV'. Another consistently RED-rated company reiterated this and added that actions are needed because of the propensity of companies to try to "escape unnoticed" from rules. The companies report however that so far, the ratings have had no impact on sales and their 
business in general although one company expressed that they do have some clients who specifically ask for their compliance certificates before undertaking business with them. Thus, a compliance rating received from the LLDA was very useful.

However there were still a number of companies who have not yet reached compliance despite exposure to media. Other than bad image though, there have been no documented direct action/pressure (actual boycotts) monitored by the PDP to date. No actual lowering of sales, collective action, complaints and direct action on the noncompliant companies have been observed as an effect of the disclosure. A comment from one of the BLACKrated companies interviewed perhaps can shed some explanation about this:

"disclosure of our rating was out in the newspapers and on TV morning and evening news...but environmental awareness of the common Filipino is not high...especially class $C$ not very concerned...they may hear of it but it won't stop them from buying our product or eating at our restaurant..we [Filipinos] are forgiving and forgetful...there is no retention...of course, our image is important especially as we are becoming an international brand"

This comment indicated that while shaming may have an impact in the short-term, companies do not feel particularly threatened because they know that their sales and/or clients are not affected. This is logical since green consumerism in the Philippines has not yet been developed. The company representative identified structural/infrastructure challenges as well as lack of technology for their sector. The price of compliance is deemed high and unaffordable. Here, despite the Filipino concept of shame and importance of reputation, companies also still consider business bottom-lines with regard to pollution abatement actions.

The evaluation of the program implementation indicated that the limited information flows to those who can possibly respond to pollution news hindered the public pressure mechanism to fully function. Pollution control officers of companies with both negative and positive ratings interviewed for the research expressed that the ratings were known mainly by their department (or those in charge of compliance), and upper managers. But that in general, other departments in the company were not aware except when the company publishes or announces the awards received. This suggests that the current dissemination platforms to the rated companies are not sufficient.

Other factors may include over-estimation of the capacity of the media to reach its intended recipients (limited media coverage and circulation, lack of reading culture) and the capacity of the recipients to respond. It seemed that shaming alone or mere disclosure is not enough to fully transform and influence sustainable behaviour of companies. More recent literature such as [5] and [15] have both expressed some caution in relying mainly on external pressures generated by disclosure programs in motivating companies to improve environmental performance for developing countries. The former cites the findings of [15] that indicate societal pressure on companies only happen under some conditions such as limited dependence on polluting firms, high income-class status and high degree of education. The latter reflects that the non-regulatory factors such as green consumerism, stock/capital markets factors and advocacy groups are not present or quite weak in developing countries. The two authors posit that regulatory action on top of disclosure may be the mechanism at play.

\subsection{Public disclosure and enhanced regulatory functions}

In interviews, officers of positive rated companies shared that aside from honour and pride, incentives such as longer validity of discharge permits and less frequent reporting mechanisms also serve to motivate the companies to exert efforts to go beyond compliance. Responses of company officers to the question, "What is the value of awards for good environmental performance?" include such statements as "if you don't follow, the LLDA will have your company closed down" and "our pressure is mainly through the regulators and not so much media or clients". These indicate that the regulatory pressure may have a bigger role in getting companies to comply. These suggest that disclosure programs might work because of the additional enforcement action or threat perceived by companies.

Previous surveys conducted on industries pertaining to the environmental user fee system within the Laguna de Bay Region, similarly find that regulatory threat and sanctions are foremost in the minds of companies. The impact evaluation study of the Laguna de Bay's Environmental User Fee System [16] indicated that firms surveyed within Laguna de Bay perceive governments in general as the main source of pressure; clients, community and environmental groups were ranked $2^{\text {nd }}$ and $3{ }^{\text {rd }}$. Creditors, investors were not perceived as significant sources of pressure. Another survey on 10 industries participating in the PDP regarding their attitudes and perceptions of the program concluded that companies are more concerned about legal sanctions and their image more than public pressure [17].

It is to be noted that while the PDP is projected by the LLDA as a cost-effective law enforcement mechanism, they have failed to take advantage of the opportunities to enhance their regulatory instruments that are presented by the program. For instance, the rating process would allow the authority to consolidate and organize monitoring data making it convenient to identify noncompliant companies from the good performers. This would also allow the authority to undertake prioritization and planning more strategic monitoring or enforcement action. It is logical for the authority to focus on the priorities for inspections and enforcement action especially that it has meagre resources. However, in practice, limited follow-up monitoring and sanctions have been undertaken for noncompliant companies under the PDP. From previous discussions, a number of the noncompliant (BLACK-rated) companies did not have any follow up ratings or monitoring actions.

\section{Conclusion}

The study monitored the changes in environmental performance of companies included in the Public Disclosure Program and found patchy outcomes: while the trend is for businesses to improve rather than to decline in ratings, the lack of follow-up data for almost half of the firms make it difficult to generalize the conclusions about the effectiveness of the program in generating sustainable behaviour of businesses in the Laguna de Bay region.

The analysis using program evaluation and logic models revealed a number of implementation and monitoring inadequacies that served to explain the patchy outcomes monitored. Information flows were a good indicator for determining strength and potentials for the source of pressure. Weak information flows indicated that target receivers of information were not reached and that the dissemination platforms utilized by the program were insufficient. Furthermore, disclosure efforts have been largely loose and untargeted which could also have hampered the program's potentials to be effective. Suggestions for program implementers include the need to expand dissemination channels and to identify specific target recipients for the information.

The reconstructed program logic indicated that the program was hoped to work through honouring and shaming as well as public pressure mechanism. While some evidence for the former have been observed, there was little pressure generated from the public. It was discovered that improved environmental behaviour by businesses may be due to the enhanced regulatory pressure 
activated by the program. Mere disclosure alone was found to be insufficient in generating voluntary improvement of environmental performances for the business sector especially since external pressures from communities and markets are still currently weak in the region. Regulators are still the primary source of pressure and implementors would do well to heed this by ensuring that enforcement actions (whether through additional inspections or legal action) are pursued.

This study recognizes the multiple benefits that may be derived from environmental information disclosure programs. The potentials for disclosure programs to be effective in generating sustainable behavior by businesses especially in countries like the Philippines exist although it is largely dependent on the degree of understanding of the actual mechanisms (and logic) that will make the program work, thoughtful implementation and considerations of context.

\section{Acknowledgements}

The author wishes to express their utmost gratitude for the financial support of the Japanese Government (Monbukagakusho: MEXT) and for Professors Matsushita, Matsumoto and Obata for their guidance and support. She also wishes to thank the officers and staff of Laguna Lake Development Authority for valuable interviews and for providing data for the research.

\section{References}

[1] Dasgputa S,Wheeler D, Wang H.. Disclosure strategies for pollution control. International yearbook of environmental and resource economics 2006/2007. A survey of current issues, ed. T. Teitenberg and H. Folmer, 93-119. Northampton, MA: Edward Elgar.

[2] Wang H,Bi J, Wheeler D, Wang J, Cao D, Lu G, Wang Y.Environmental Performance Rating and Disclosure: China's Green-Watch Program. Journal of Environmental Management2004: 71(2), 123-133.

[3] Powers N, Blackman A, Lyon T, \&Narain U.Does Disclosure Reduce Pollution? Evidence from India's Green Rating Project. Resources for the Future. Environment and Development. Discussion Paper Series. October 2007. Retrieved from http://www.rff.org/RFF/Documents/EfD-DP-o8-27.pdf

[4] Blackman A, Afsah S, Ratunada D.How do Public Disclosure Pollution Control Programs Work? Evidence from Indonesia. Human Ecology Review, 2004: 11(3).

[5] B. Van Rooij. Greening Industry Without Enforcement? An Assessment of the World Bank's Pollution Regulation model for Developing Countries. Law E Policy2010: 32(1).

[6] Bruijn T, Norberg-Bohm V.Voluntary, Collaborative, and Information-Based Policies: Lessons and Next Steps for Environmental and Energy Policyin the United States and Europe.2001. Energy Technology Innovation Project, Belfer Center for Science and International Affairs and Regulatory Policy Program, Center for Business and Government, Kennedy School of Government, Harvard University.

[7] Weiss C. Evaluation: Methods for Studying Programs E Policies and edition. Prentice Hall. Upper Saddle River, NJ. 1998

[8] World Bank. Philippines Environment Monitor 2003. Manila Country Office, Pasig City, Philippines. 2003

[9] Torres C. Design of Public Disclosure Program for the Laguna de Bay Region. Final Report, LISCOP Component 2. Laguna Lake Development Auhtority. Pasig City, Philippines. 2005.

[10] Resources, Environment and Economics Center for Studies, Inc (REECS). Main Report. Strengthening Public Disclosure Program. Report No. 3. Strengthening Environmental Enforcement and Compliance Capacity Technical Assistance Project. Report submitted to the Environmental Management Bureauu, DENR. Philippines. 2003.

[11] Mercado E, Santos-Borja A. The LLDA's Public Disclosure Program: A Tool for Pollution Control and Environmental Governance. (undated).
[12] Manda E, Santos-Borja A, Mercado E. LLDA's Fame and Shame Approach: An Effective Tool in Pollution Control. 2009.Accessed from http://rcse.edu.shiga-u.ac.jp/govpro/plan/20oglist/11wlc13_wuhan/ilbm_expert_group_meeting/wlc1 3_papers/13_mandapaper.pdf

[13] World Bank. Greening Industry: New Roles for Communities, Markets and Governments. World Bank Policy Research Report. 200o. Oxford University Press, New York.

[14] Mercado E. Interview by author. LLDA office, Taytay, Rizal. July 15, 2010.

[15] Blackman A. Alternative Pollution Control Policies in Developing Countries. Review of Environmental Economics and Policy2010: 4:2.

[16] Catelo MA, Sajise A, Darvin BA, Ramirez PJ. Impact Evaluation of the Environmental User Fee System: A Stakeholder Perspective. Economy and Environment Program for Southeast East Asia-IDRC Technical Paper No. 2007-07-17.

[17] Cabral H. Public Disclosure as a communication approach for enhancing compliance of industries with water quality standards in Laguna de Bay, Philippines. Master's thesis. 2009. University of the Philippines Los Banos, Philippines. 